Available online on 15.03.2019 at http://jddtonline.info
Journal of Drug Delivery and Therapeutics
(c) 2011-18, publisher and licensee JDDT, This is an Open Access article which permits unrestricted
non-commercial use, provided the original work is properly cited

Open $\mathcal{O}_{\text {Access }}$

Review Article

\title{
A brief review on Kollidon
}

\author{
Jagtap Pratik, Tagad Rupesh, Shendge Raosaheb* \\ Department of Pharmaceutics (PG), Sanjivani College of Pharmaceutical Education and Research, Kopargaon
}

\begin{abstract}
Polyvinylpyrrolidone includes soluble and insoluble grades; soluble grades are synthesised by the mechanism of polymerization, the free radical polymerization into the water by using hydrogen peroxide as an initiator, the mechanism which terminates the polymerisation reaction makes it probable to produce soluble polyvinylpyrrolidone of about any molecular weight. Cross-linked polymer shows yield through popcorn polymerisation of an $\mathrm{N}$-vinylpyrrolidone which gets insoluble polyvinylpyrrolidone. Kollidon is in the market as a brand name for polyvinylpyrrolidone, a kollidon family now is a set of common excipients based on polyvinylpyrrolidone for use in the pharmaceutical industry. They have a great variety of applications in an oral formulation; the functions of oral formulation encompass fast disintegration, sustain drug release, solubility, bioavailability enhancement, and stabilize the active ingredient. Kollidon containing a mixture of polyvinyl acetate plus povidone are generally used in the formation of sustained release formulation. Owing to their high molecular weight, are recognized as a suitable vehicle for producing sustained release drug delivery system. In this review paper, applications of different grades of kollidon are organized in the form of tables and reviewed critically. Current literature of patents on kollidon based formulations is also presented.
\end{abstract}

Keywords: Polyvinylpyrrolidone, polymerization, sustained release drug delivery

Article Info: Received 04 Feb 2019; Review Completed 07 March 2019; Accepted 08 March 2019; Available online 15 March 2019

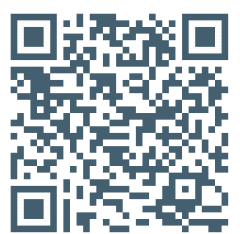

Cite this article as:

Jagtap P, Tagad R, Shendge R, A brief review on Kollidon, Journal of Drug Delivery and Therapeutics. 2019; 9(2):PageNo. http://dx.doi.org/10.22270/jddt.v9i2.2539

*Address for Correspondence:

Dr. Raosaheb Sopanrao Shendge, Professor, Department of Pharmaceutics (PG), Sanjivani College of Pharmaceutical Education and Research, Pune University, Kopargaon, India.

\section{INTRODUCTION}

Kollidon grades among the synthetic excipient it is said to be one of the essential substances in the pharmaceuticals and cosmetic industries. The soluble kollidon grades were synthesized by w. reppe in 1939; a number of the product followed by including insoluble grades, copolymeristates and sustain release preparation for numerous applications. The insoluble grades (crospovidone) are prepared using a physical cross-linking process as popcorn polymers of vinyl pyrrolidone. kollidon VA 64 (Copovidone) is a water-soluble copolymeristate of vinylpyrrolidone, and vinyl acetate is mainly used as a binder in tablet, granules, capsules, and coating process. For sustained release purpose, a mixture of polyvinyl acetate and povidone in a ratio of $8: 2$ is available under the name of kollidon SR which mainly used as controlled release system. Kollidon soluble grade has a wide range of applications in the oral formulation include enhancement in solubility and bioavailability of the drug, immediate release, taste masking, increase binding capacity, stability, improve the activity of pore formation. The examples of soluble grade of kollidon (Povidone) are kollidon 12 PF, 17 PF, 25, 30, 90F, kollidon VA64 (Copovidone), insoluble grade (Crospovidone) are kollidon CL, CL-F, CL-SF, CL-M and kollidon SR grade which is mixture of polyvinyl acetate and povidone in ratio of 8:2 for sustain

ISSN: 2250-1177 release purpose. All the above grade of kollidon has broad application in formulation and development. However, in the current review, we have focused critically on applications of following grades of kollidon vis kollidon soluble (12PF, 17PF, 30, 90, VA64), kollidon insoluble (CL-M, CL-F, CL-SF), and kollidon SR. The grades on which spacious research has been published were selected for review. Hence the objective of the present manuscript is to make a compilation review of research publications and patents on various applications of some chosen grades of kollidon.[1]

\subsection{Soluble kollidon grades (Povidone)}

The following are the examples of soluble kollidon categories such as kollidon $12,12 \mathrm{PF}, 17 \mathrm{PF}, 25,30,30 \mathrm{LP}, 90 \mathrm{~F}$. Amongst the above categories, Kollidon 12PF, 17PF, 30, 90 were selected for review as these having research literature published on it.

\section{2. kollidon $® 12 P F, 17 P F$}

The low molecular grades, kollidon $12 \mathrm{PF}, 17 \mathrm{PF}$ are intended for solubilising agents, dispersants and crystallisation inhibitors particularly for injectable

A current literature review on kollidon 12PF Gayathri $\boldsymbol{K}$ et al. [2] shows that Kollidon $12 \mathrm{PF}$ which is having low molecular weight polyvinylpyrrolidone generally used as a 
solubilizing agent and also inhibits crystallization used in the preparation of immediate release formulations and also reducing printing temperature in 3D printing method in order to hold thermolabile and less melting temperature drugs. L. S. May et al. [3] prepared a solid dispersion of docetaxel utilising binary and ternary method using Kollidon 12PF, Soluplus, Lutrol F68 and hydroxyl propyl beta- cyclodextrin in various weight proportions. Piero Piccioni et al. [4] He studied screening systems for initial stage formulation development by solubility parameter using the solid dispersion of itraconazole with hot melt extrusion and quench cooling technique by using kollidon 17PF, Eudragit $\mathrm{E}$ (EPO) and Soluplus.

Table 1: The reported literature on Kollidon 12PF, 17PF.

\begin{tabular}{|c|c|c|c|c|}
\hline $\begin{array}{l}\text { Name of } \\
\text { the drug }\end{array}$ & Method & Dosage form & Result & Ref \\
\hline Ramipril & $\begin{array}{l}\text { Low temperature fused deposition modelling } \\
\text { (FDM) 3D printing of thermolabile drugs }\end{array}$ & $\begin{array}{l}\text { Drug-loaded } \\
\text { filament }\end{array}$ & $\begin{array}{l}\text { Enhance solubility of the } \\
\text { drug }\end{array}$ & [5] \\
\hline & Binary and ternary solid dispersion & & & \\
\hline Docetaxel & & $\begin{array}{l}\text { Solid } \\
\text { dispersion }\end{array}$ & $\begin{array}{l}\text { Enhanced solubility of the } \\
\text { drug }\end{array}$ & [3] \\
\hline
\end{tabular}

\subsection{Kollidon $® 30$}

W. Linka. [6] studied the three formulations of matrices show the usefulness of Kollidon K30 and HPMC in the technology of hydrophilic matrices with ketoprofen, Kollidon K30 accelerated the release of ketoprofen from tablets of formulation

\subsection{Kollidon $® 90 F$}

Kollidon 90F having various properties like high binding capacity the required quantity is $2 \%$ or even less, stabilisation of oral dosage form, film-forming agent, kollidon 90F having good solubility in water and alcohol it can be used as a thickener for an aqueous-alcoholic solution for oral application
A current literature review on kollidon 90F A. Fini et al. [7]used kollidon90Fwith combination of appropriate excipient for obtaining taste masking, orally disintegrating tablets and delay the release of ibuprofen using conventional and straightforward techniques. Dashevsky et al. [8] he used Polyvinylpyrrolidone (Kollidon90F) superior to HPMC and HPC as a binder for the swelling layer about binding (adherence to capsule) and increase disintegration properties of the dosage form. B.B. Alsulays et al. [9]studied the influence of the molecular weight of carriers and processing parameters on the extrudability, drug release, and stability of fenofibrate formulations processed by hotmelt extrusion.

Table 2: The reported literature on kollidon30, 90F.

\begin{tabular}{lllll}
\hline $\begin{array}{l}\text { Name of } \\
\text { the drug }\end{array}$ & Method & $\begin{array}{l}\text { Dosage } \\
\text { form }\end{array}$ & Result & Ref \\
\hline ketoprofen & Direct compression & Tablet & Enhanced the release of drug from tablet & [10] \\
ibuprofen & $\begin{array}{l}\text { Orally disintegrating and delayed } \\
\text { release Tablet }\end{array}$ & Delayed the release and masked taste of the bitter drug & [7] \\
& $\begin{array}{l}\text { Capsule-Based Drug Delivery } \\
\text { System with Pulsatile Drug Release }\end{array}$ & Capsule & Increased binding capacity to adhere capsule \\
\hline
\end{tabular}

\subsection{Insoluble kollidon grades(Crospovidone)}

Crospovidone, a hydrophilic crosslinked homopolymer of $\mathrm{N}$ vinyl pyrrolidone, has been reported as one such alternative. Based on its porosity as well as its ability to rapidly absorb water, swell, and yet remain insoluble, it is a biologically inert, synthetic polymer whose synthesis does not involve any organic solvents a polymerisation process in water manufactures the Kollidon CL grades without any organic solvents. This polymerisation produces a mainly physically cross-linked insoluble polyvinylpyrrolidone in the form of a popcorn polymer. There are various grades of Kollidon CL, CL-F, CL-SF, and CL-M. Among this grade CL-M, CL-F, CL-SF was selected because most of the literature are published on these grade showing increase in solubility, bioavailability, immediate release of drug from dosage, increase sphericity of pellets, etc.

\subsection{Kollidon ${ }^{\circledR} C L-M$}

KollidonCL-Misused as the standard disintegrant for all kind of different tablet formulations Main reasons for selection of kollidon CL-M is the strongest disintegration power with benefits, especially in large tablets. It has advantages compared to other disintegrants which are dependent on different chemistry due to disintegration and dissolution speed.

A literature review on kollidon CL-M shows that it has been used extensively in the formulation of A. Maroni et al. [11]studied Preliminary study on free and applied films in which Kollidon CL-M was used as superdisintegrant and shows the activity of pore-formation in multi-unit pulsatile drug delivery system. Y. Gonnissen et al. [12]studied the effect of maltodextrins and superdisintegrants on the tablet properties and evaluated directly compressible powders coprocessed via spray drying. The disintegration time of tablets containing a coprocessed superdisintegrant (kollidon CL-M) was longer than other excipients.H. Friedrich et al. [13]improved the dissolution rate of carbamazepine and nifedipine by adsorbing solutions of the drugs in hydrophilic nonvolatile or volatile solvents onto carriers (Aerosil, Kollidon CL-M) with a large surface area. 
Table 3: The reported literature on kollidon CL-M.

\begin{tabular}{lllll}
\hline Name of the drug & Method & Dosage form & Result & Ref \\
\hline Acetaminophen & Pulsatile drug delivery & Capsule & Increase the activity of pore-formation & [14] \\
$\begin{array}{l}\text { Acetaminophen } \\
\begin{array}{l}\text { Carbamazepine } \\
\text { and nifedipine }\end{array}\end{array}$ & $\begin{array}{l}\text { Direct compression co-processed } \\
\text { via spray drying }\end{array}$ & Tablet & $\begin{array}{l}\text { Increase in disintegration time of } \\
\text { formulation }\end{array}$ & $\begin{array}{l}\text { Increase the dissolution rate and drug } \\
\text { release from the formulation }\end{array}$ \\
\hline
\end{tabular}

\subsection{Kollidon® $C L-F, C L-S F$}

Kollidon CL-SF is the most excellent crospovidone grade for disintegration purposes, and it has a good disintegration power and fewer surface defects of the tablets after humid storage. This grade is perfect for fast disintegrating buccal tablets

A current literature review on kollidon CL-SF based research publication N. C. Loka et al. [15] shows that immediate release pellets were prepared by wetted mass extrusion method, and markedly improved the sphericity of the pellets produced by marumerization. A. Amelian et al. [16]formulated orally disintegrating loratadine tablet manufactured with co-processed mixture (Kollidon CL-F, CL$\mathrm{SF}$ ) by direct compression method, prepared tablets was of appropriate mechanical properties, disintegration time below 30 seconds was observed in formulation with crospovidone as disintegrant. M. Saurabh et al. [17]studied an integrated, quality by design (QbD) approach for design, development, and optimization of an orally disintegrating tablet formulation of carbamazepine; he found that kollidon CL-SF concentration was optimum to prepare orally disintegrating tablet formulation of carbamazepine of desired attributes; thus it was found to be best sublimating agent and disintegrant, respectively. $\boldsymbol{R}$. Sheshala et al. [18]formulated orally disintegrating tablets of sumatriptan succinate, the formulation containing kollidon CL-SF disintegrated in the oral cavity within $41 \mathrm{~s}$ and released more than $90 \%$ of the drug within 15 minute.

Table 4: The reported literature on kollidonCL-F, CL-SF.

\begin{tabular}{lllll}
\hline Name of the drug & Method & Dosage form & Result \\
\hline Caffeine & Extrusion spheronization & Pellets & Improve in sphericity of pellets \\
Loratadine & Direct compression & $\begin{array}{l}\text { Orally } \\
\text { disintegrating tablet }\end{array}$ & $\begin{array}{l}\text { Improved mechanical properties of tablet } \\
\text { and disintegration time }\end{array} \quad[16]$ \\
Carbamazepine & Direct compression & $\begin{array}{l}\text { Orally } \\
\text { disintegrating tablet }\end{array}$ & $\begin{array}{l}\text { Improved in disintegration time of } \\
\text { formulation }\end{array}$ \\
$\begin{array}{l}\text { Sumatriptane } \\
\text { succinate }\end{array}$ & Direct compression & $\begin{array}{l}\text { Orally } \\
\text { disintegrating tablet }\end{array}$ & $\begin{array}{l}\text { Improved in disintegration time of } \\
\text { formulation }\end{array}$ \\
\hline
\end{tabular}

\subsection{Kollidon $® S R$}

Kollidon SR is spray dried polyvinyl acetate containing also soluble poly-vinylpyrrolidone (povidone) in the ratio 8:2, kollidon SR is nominally an $80 / 19(\mathrm{w} / \mathrm{w})$ mixture of polyvinyl acetate and polyvinylpyrrolidone, respectively. Kollidon SR can be used for the production of the sustained release matrix preparations of tablets, pellets, and granules. The recommended technology for the production of sustained release matrix tablets based on Kollidon SR is the direct compression. The excellent flowability and compressibility of KollidonSR are the main factors which make this excipient particularly suitable for the manufacture of sustained release matrix tablets obtained by direct compression

An updated literature review on Kollidon SR based formulations revealed that it could be used in sustaining the release, bioavailability enhancement of drugs. M. Shergill et al. [21]formulated sustained release solid dispersion oral tablet containing water-insoluble drug by using kollidon SR, and another excipient, shows enhanced solubility of drug while also sustaining its release. Özgüney et al. [22] prepared extended release kollidon SR mini-matrices by hotmelt extrusion, kollidon SR were used as the carrier for drug which shows plasticizing effect, and hot-melt extruded successfully prepared using kollidon SR. Meulenaar et al. [23]kollidon SR used for preparation of an extended-release formulation of capecitabine by using In Vitro-In Vivo correlating modelling, kollidon SR in this formulation used as carrier for spray drying.W. Sakr et al. [24]studied effect of Kollidon SR comparison with other polymers on the release of Albuterol Sulphate from matrix tablets, he studied kollidon SR with combination of (HPMC and Carbopol) were found to be potential candidates for the development of extended release of Albuterol Sulphate matrix tablets, also found that kollidon SR to be a useful release rate modifier for highly water-soluble low dose drug. S.H. Song et al. [25]formulated controlled-release pelubiprofen tablet using kollidonSR, kollidon SR containing formulation was found to be the most promising and stable for 6 months in an accelerated stability test and 24 months in a long-term storage test. Control release achieved from the tablet was limited at $\mathrm{pH} 1.2$, but gradually increased at pH6.8 with a surface-erosion was studied. Sahoo et al. [26] formulated sustained-release dosage form of verapamil hydrochloride by solid dispersion technique using eudragit RLPO andkollidonSR, drug release study from dosage form was studied, kollidon containing dosage form was extended till 8 hr. J.L. Arias et al. [27] studied the dosage form containing kollidon SR colloidal particles which were used as vehicles 
for oral morphine delivery in pain treatment, also analysed that the release studies showed a biphasic profile very suitable to achieve a sustained release of morphine during $24 \mathrm{~h}$. Therefore, they have concluded that kollidon SR suspensions are very promising candidates for the formulation of oral morphine systems with a sustained release. E. Palazi et al. [28] enhanced solubility of waterinsoluble drug felodipine by melt-extrusion process and sustained release action of drug was achieved using kollidon SR. C. Wiranidchapong et al. [29] investigated the effect of storage temperature on drug release from matrices containing ibuprofen in Kollidon SR, the matrix tablets were produced by direct compression and then kept at 30 and $45^{\circ} \mathrm{C}$ for 3 months. Magdalena Czajkowska et al. [30] formulated Prolonged-release mini tablets with carbamazepine Prolonged release of carbamazepine was obtained from both matrix-type by using kollidon SR. $\boldsymbol{S}$. Engineer et al. [31] studied the effects of temperature and humidity on tablets containing diphenhydramine hydrochloride which was prepared using direct compression technique with Kollidon SR; sustained-release tablets composed of Kollidon SR have been shown to be heat and moisture sensitive. J. Grund et al. [32] studied the kollidon SR and other polymer properties on direct compression and drug release from water-insoluble controlled release matrix tablets and compared with regard to their properties in dry and wet state.

Table 5: Reported literature on kollidon SR.

\begin{tabular}{|c|c|c|c|c|}
\hline Name of the drug & Method & Dosage form & Result & Ref \\
\hline Disulfiram & Hot-melt extrusion & $\begin{array}{l}\text { Solid dispersion } \\
\text { tablets }\end{array}$ & $\begin{array}{l}\text { Enhanced solubility of drug while also } \\
\text { sustaining its release }\end{array}$ & [33] \\
\hline $\begin{array}{l}\text { Ibuprofen, } \\
\text { theophylline }\end{array}$ & Hot-melt extrusion & Tablet & $\begin{array}{l}\text { Shows plasticising effect and extended the } \\
\text { drug release }\end{array}$ & [22] \\
\hline Capecitabine & Spray drying, co-spray drying & Tablet & Co-spray drying was successfully achieved & [23] \\
\hline Albuterol Sulphate & Direct compression & Tablet & $\begin{array}{l}\text { Kollidon SR was found to enhance the } \\
\text { mechanical properties of tablets increasing } \\
\text { hardness and decreasing friability. }\end{array}$ & [34] \\
\hline Pelubiprofen & Wet granulation & Tablet & $\begin{array}{l}\text { Stability was achieved and controlled the } \\
\text { release of the tablet at } 1.2 \mathrm{pH} \text {. }\end{array}$ & [35] \\
\hline $\begin{array}{l}\text { Verapamil } \\
\text { hydrochloride }\end{array}$ & $\begin{array}{l}\text { Solid dispersion, tablets were } \\
\text { compressed with hydraulic } \\
\text { pellet press. }\end{array}$ & Tablet & $\begin{array}{l}\text { Tablet extends the release of drug till } 8 \mathrm{hr} \text { by } \\
\text { using kollidon SR. }\end{array}$ & [36] \\
\hline Morphin & Incorporation & Oral Suspension & Sustained the release of drug & [27] \\
\hline Felodipine & Hot-melt extrusion & $\begin{array}{l}\text { Amorphous } \\
\text { solid dispersion }\end{array}$ & $\begin{array}{l}\text { Solubility was enhanced as well as sustained } \\
\text { the release of drug by using kollidon SR. }\end{array}$ & [37] \\
\hline Ibuprofen & $\begin{array}{l}\text { Matrix tablet prepared by } \\
\text { direct compression }\end{array}$ & Matrix tablet & $\begin{array}{l}\text { Stability of ibuprofen seems to be increased } \\
\text { under various conditions. }\end{array}$ & [29] \\
\hline Carbamazepine & Direct compression & $\begin{array}{l}\text { Matrix mini } \\
\text { tablet }\end{array}$ & $\begin{array}{l}\text { Prolonged the release of drug by matrix } \\
\text { tablet prepared using kollidon SR }\end{array}$ & [30] \\
\hline $\begin{array}{l}\text { Diphenhydramine } \\
\text { HCL }\end{array}$ & Direct compression & Tablet & shows heat and moisture sensitivity & [31] \\
\hline
\end{tabular}

\subsection{Kollidon ${ }^{\circledR V A 64}$ (Copovidone)}

The Kollidon VA 64 is manufactured by free-radical polymerisation of 6 parts of $\mathrm{N}$-vinylpyrrolidone and 4 parts of vinyl acetate in 2-propanol, it has $\mathrm{pH} 3-7$ (10\% in water), Kollidon VA 64 in formulations for solid dosage forms, the particle size distribution can be of considerable importance. This particularly applies to the manufacture of tablets. However, it also has importants in solutions, e. g. film-coating solutions for tablets, as the dissolution rate and the dusting properties depend on the proportions of coarse and fine particles respectively, it has good binding and filmforming properties, their affinity to hydrophilic and hydrophobic surfaces and the relatively low hygroscopicity. Because of these properties, copovidone is used as a binder in the production of granules and tablets by wet granulation, as a dry binder in direct compression, as film former in coatings on tablets, as a protective layer and sub coat for tablet cores, as a film-forming agent in sprays and as a matrix.

Current literature review on kollidon VA64 revealed that mostly solid dispersions were prepared to increase solubility and bioavailability of water-insoluble drugs. K. Chmiel et al. [38] identified physically stable concentration of amorphous solid dispersion in case of Flutamide with Kollidon VA64. $\boldsymbol{R}$. Dreu et al. [39] formulated multiple-unit tablet containing enteric coated pellets by using kollidon VA64 as binder, kollidonVA64 was found to be optimal as a cushioning excipient. T. Vojinovic et al. [40] prepared ternary solid dispersions with hydrophilic polymer kollidon VA64 and surface adsorbent for improving dissolution rate of carbamazepine, he analyzed that ternary solid dispersion prepared with kollidonVA64 hydrophilic polymer and adsorption carrier resulted in significant improvement of carbamazepine dissolution rate. F.Tres et al. [41]studied the $\mathrm{pH}$-dependent controlled release of indomethacin by using 
kollidonVA64; the experiments were performed at $\mathrm{pH} 2$ to mimic the stomach conditions and $\mathrm{pH} 6.8$ to simulate the post-stomach conditions. He found that only indomethacin present in the $5 \%$ extrudate exhibits a detectable dissolution rate at $\mathrm{pH} 2$, pointing to a drug release mechanism dependent on the highly water-soluble copovidone. He also analysed that the proposed $\mathrm{pH}$-dependent dissolution model can be applied to a wide range of poorly soluble ionizable drugs and may be employed in the future to control and modulate the drug release in the stomach and small intestine. Maddineni et al. [42] studied, melt extrusion technology in combination with Kollidon VA 64 produced chemically and physically stable extrudates with higher drug loading and enhanced drug release. Nifedipine was found to be miscible in Kollidon VA 64 up to $40 \%$ w/w drug loading without demonstrating the need for any processing aids. $\boldsymbol{R}$. $\boldsymbol{S}$. Chaudhary et al. [43] kollidon VA 64 and a combination of Kollidon VA 64 with Kollidon VA 64 fine as an excipient in direct compression process of tablets, the combination of the two grades of material was evaluated for capping, lamination, and excessive friability. He found that tablets with hardness ranging between 19 and $21 \mathrm{kp}$, with no friability, capping, or lamination issue. D. Patel et al. [44] formulated user-friendly metered-dose transdermal spray (MDTS) of lopinavir; he found that formulation containing 5 $\% \mathrm{w} / \mathrm{v}$ of Kollidon VA 64 had best sprayability and volatilisation property. Significantly increase in permeation enhancement and steady-state transdermal flux. K. Kolter et al. [45] studied structure and dry binding activity of different polymers, including kollidon VA 64, the tablets prepared using kollidon VA 64 showed an improvement in mechanical properties (hardness, friability) with increasing dry binder concentration and greatest binding efficacy. $\boldsymbol{E}$. Castellanos Gil et al. [46] formulated oral controlled delivery system for propranolol hydrochloride by using wet granulation process. He studied the ability of subcoating with Kollidon VA 64 as a barrier to water penetration in matrix cores; he observed that kollidon VA 64 not only increases the mechanical properties of tablets (less friability) but also reduces the amount of absorbed water from the air in tropical stability condition. N. Solanki et al. [47] formulated 3D printed tablet for rapid drug release by fused deposition modelling (FDM): screening polymers for drug release, drug-polymer miscibility, and printability, he found that mixture of Kollidon VA64 and Affinisol $15 \mathrm{cP}$ is suitable polymer system for 3D printing and rapid drug release.

Table 6: The reported literature on kollidon VA 64

\begin{tabular}{|c|c|c|c|c|}
\hline Name of the drug & Method & Dosage form & Result & Ref \\
\hline Flutamide & Solid dispersion & $\begin{array}{l}\text { Amorphous solid } \\
\text { dispersion }\end{array}$ & $\begin{array}{l}\text { The amorphous solid dispersion was identified as } \\
\text { physically stable }\end{array}$ & [38] \\
\hline Carbamazepine & Ternary solid dispersion & $\begin{array}{l}\text { Amorphous solid } \\
\text { dispersion }\end{array}$ & $\begin{array}{l}\text { The result showed improvement of carbamazepine } \\
\text { dissolution rate }\end{array}$ & [40] \\
\hline Indomethacin & Extrusion spheronization & Extrudes & $\begin{array}{l}\text { the } \mathrm{pH} \text {-dependent controlled release of } \\
\text { indomethacin was carried out successfully }\end{array}$ & [41] \\
\hline Celecoxib & melt-quenching & $\begin{array}{l}\text { Amorphous solid } \\
\text { dispersion }\end{array}$ & Increase in bioavailability was determined. & [48] \\
\hline Nifedipine & Hot-Melt Extrusion & Extrudes & $\begin{array}{l}\text { Produced physically and chemically stable extrudes } \\
\text { with enhanced flow characteristics and excellent } \\
\text { stability. }\end{array}$ & [49] \\
\hline $\begin{array}{l}\text { Esomeprazole } \\
\text { Magnesium }\end{array}$ & Direct compression & Tablet & $\begin{array}{l}\text { By using kollidon VA } 64 \text { friability, capping, or } \\
\text { lamination issue were minimised. }\end{array}$ & {$[50]$} \\
\hline Lopinavir & & $\begin{array}{l}\text { Metered-dose } \\
\text { transdermal spray }\end{array}$ & $\begin{array}{l}\text { Good sprayability, the formulation was stable, and } \\
\text { the permeation rate was enhanced by using kollidon } \\
\text { VA } 64\end{array}$ & [51] \\
\hline $\begin{array}{l}\text { Dicalcium } \\
\text { phosphate } \\
\text { formulation (water- } \\
\text { insoluble) and } \\
\text { vitamin C (Water } \\
\text { soluble) was used } \\
\text { for the study. }\end{array}$ & Direct compression & Tablet & $\begin{array}{l}\text { Shows increase in dry binder concentration and } \\
\text { greatest binding efficacy. }\end{array}$ & [45] \\
\hline $\begin{array}{l}\text { Propranolol } \\
\text { hydrochloride }\end{array}$ & Wet granulation & Tablet & $\begin{array}{l}\text { Kollidon VA } 64 \text { increase mechanical properties of } \\
\text { tablet and also stability }\end{array}$ & [46] \\
\hline Nimodipine & Hot-Melt Extrusion & Solid dispersion & $\begin{array}{l}\text { Effect of high storage temperature on the } \\
\text { recrystallisation rate during the dissolution of } \\
\text { Nimodipine-Kollidon VA64 solid dispersions }\end{array}$ & [52] \\
\hline Haloperidol & Hot-Melt Extrusion & 3D printed tablet & Enhanced drug release & [53] \\
\hline
\end{tabular}




\subsection{Patents on kollidon based formulations}

Patents on kollidon based formulations are presented in Table. Patents were filed on the applications of various grades of kollidon-vis. These grades were used in the formulation of drugs with diverse applications such as improvement in solubility, bioavailability, enhanced absorption, etc. P. Pilgaonkar et al. [54] patented the novel sustained release dosage form comprising an active agent and a combination of a non-swelling $\mathrm{pH}$-dependent release retardant and a non-swelling $\mathrm{pH}$-independent release retardant polymer which provides $\mathrm{pH}$-independent drug release for a considerable period of time after administration, kollidon SR used as sustained release polymer and also other kollidon grades were used in the preparation of formulation.V. Kanikanti et al. [55] patented solid pharmaceutical formulation with delayed release, the invention relates to a solid pharmaceutical preparation with delayed release of the active ingredients which is suitable in particular for use in animals. Kollidon SR used as delayed release polymer in combination with other excipients. $\boldsymbol{K}$. Kolter et al. [56] patented active ingredient-containing floating forms comprising polyvinyl acetate and polyvinylpyrrolidone, their use, and production, invention relates to oral dosage forms comprising one or more active ingredients, a formulated mixture of polyvinyl acetate and polyvinylpyrrolidone, where appropriate other excipients for producing the dosage form, wherein they float on gastric fluid and display delayed release of active ingredient. Talwar et al. [57] patented an orally administered controlled drug delivery system providing temporal and spatial control; the Swelling agent belongs to a class of compounds known as superdisintegrants(e.g., cross-linked polyvinylpyrrolidone) used as an immediate release component in the present invention. Roser et al. [58] patented rapidly soluble oral solid dosage forms, methods of making same, and compositions thereof; in this invention kollidon and its grades were used as a binder in the formulation. Bockbrader et al. [59] patented solid pharmaceutical compositions containing pregabalin; the composition includes a matrix forming agent and a swelling agent and is suitable for once-daily oral administration. The exemplary matrix forming agents include mixtures of polyvinyl acetate and polyvinylpyrrolidone, and exemplary swelling agents include cross-linked polymers of polyvinylpyrrolidone.

Table 7: Patents on kollidon based formulations.

\begin{tabular}{|c|c|c|c|c|}
\hline Title & Patent no & Date & Kollidon grade & Inventors \\
\hline Novel sustained release dosage form & United states patentUS $2009 / 0053310 \mathrm{~A} 1$ & $26 / 02 / 2009$ & Kollidon SR, VA 64, K30 & [54] \\
\hline $\begin{array}{l}\text { Solid pharmaceutical formulation } \\
\text { with delayed release }\end{array}$ & United States patent US 2011/0046072 A1. & $24 / 02 / 2011$ & Kollidon SR & [55] \\
\hline $\begin{array}{l}\text { Active ingredient-containing floating } \\
\text { forms comprising Polyvinylacetate } \\
\text { and Polyvinylpyrrolidone, their use } \\
\text { and production }\end{array}$ & United states patentUS $6,635,279$ B2 & $21 / 10 / 2003$ & Kollidon SR & [56] \\
\hline $\begin{array}{l}\text { an orally administered controlled } \\
\text { drug delivery system providing } \\
\text { temporal and spatial control }\end{array}$ & United States patent US 6,261,601 B1 & $17 / 07 / 2001$ & Kollidon CL-M & {$[57]$} \\
\hline $\begin{array}{l}\text { patented rapidly soluble oral solid } \\
\text { dosage forms, methods of making } \\
\text { same, and compositions thereof }\end{array}$ & United States patent US 5,762,961 & 09/06/1998 & Kollidon VA 64 & {$[58]$} \\
\hline $\begin{array}{l}\text { solid pharmaceutical compositions } \\
\text { containing pregabalin }\end{array}$ & United states patent US $8,945,620$ B2 & $03 / 02 / 2015$ & Kollidon SR & [59] \\
\hline
\end{tabular}

\section{CONCLUSION}

Kollidon is the class of vehicle available in multiple grades. It can be used as a carrier in a large variety of formulations such as immediate release, sustain release, binder, stabilizer, solubility, and bioavailability enhancer, etc. Hence the review presented in this paper can be used as a ready source for researchers using kollidon in their formulations.

\section{REFERENCES}

1. Bühler V. Kollidon - Products \&amp; Industries - Google Search [Internet]. BASF SE PharmaIngredients\&S ervices 67056Ludwigshafen,Germany. 2008 [cited 2018 Nov 22]. p. 7266. Available from:

https://www.google.co.in/search?q=basf+kollidon\&oq=basf $+\mathrm{k}$ ollidon\&aqs=chrome..69i57j015.5831j0j7\&sourceid=chrome\&i $\mathrm{e}=$ UTF-8

2. Kollamaram G, Croker DM, Walker GM, Goyanes A, Basit AW, Gaisford S. Low temperature fused deposition modeling (FDM) 3D printing of thermolabile drugs. Int J Pharm [Internet]. 2018; 545(1-2):144-52. Available from: https://doi.org/10.1016/j.ijpharm.2018.04.055
3. Lim SM, Pang ZW, Tan HY, Shaikh M, Adinarayana G, Garg S. Enhancement of docetaxel solubility using binary and ternary solid dispersion systems. Drug Dev Ind Pharm. 2015;41(11):1847-55.

4. Piccinni P, Tian Y, McNaughton A, Fraser J, Brown S, Jones DS, et al. Solubility parameter-based screening methods for earlystage formulation development of itraconazole amorphous solid dispersions. J Pharm Pharmacol. 2016; 68(5):705-20.

5. Kollamaram G, Croker DM, Walker GM, Goyanes A, Basit AW, Gaisford S. Low temperature fused deposition modeling (FDM) 3D printing of thermolabile drugs. Int J Pharm. 2018; 545(12):144-52.

6. Linka W, Kot M, Kołodziejczyk M. Application of synthetic and semisynthetic polymers (Kollidon K30 and hydroxypropylmethylcellulose) as carriers of ketoprofen in solid oral prolonged-release dosage forms. Polym Med [Internet]. 2017; 46(2):145-53. Available from: http://www.polimery.umed.wroc.pl/en/article/2016/46/2/1 $45 /$

7. Fini A, Bergamante V, Ceschel GC, Ronchi C, de Moraes CAF. Fast dispersible/slow releasing ibuprofen tablets. Eur J Pharm Biopharm. 2008; 69(1):335-41.

CODEN (USA): JDDTAO 
8. Dashevsky A, Bussemer T, Mohamad A, Bodmeier R. Process and Formulation Variables Affecting the Performance of a Rupturable Capsule-Based Drug Delivery System with Pulsatile Drug Release. Drug Dev Ind Pharm. 2004; 30(2):171-9.

9. Alsulays BB, Park JB, Alshehri SM, Morott JT, Alshahrani SM, Tiwari R V., et al. Influence of molecular weight of carriers and processing parameters on the extrudability, drug release, and stability of fenofibrate formulations processed by hot-melt extrusion. J Drug Deliv Sci Technol [Internet]. 2015; 29:189-98. Available from: http://dx.doi.org/10.1016/j.jddst.2015.07.011

10. Linka W, Kot M, Kołodziejczyk M. Application of synthetic and semisynthetic polymers (Kollidon K30 and hydroxypropylmethylcellulose) as carriers of ketoprofen in solid oral prolonged-release dosage forms. Polym Med. 2017; 46(2):145-53.

11. Maroni A, Del Curto MD, Cerea M, Zema L, Foppoli A, Gazzaniga A. Polymeric coatings for a multiple-unit pulsatile delivery system: Preliminary study on free and applied films. Int J Pharm [Internet]. 2013; 440(2):256-63. Available from: http://dx.doi.org/10.1016/j.ijpharm.2012.05.075

12. Gonnissen Y, Remon JP, Vervaet C. Effect of maltodextrin and superdisintegrant in directly compressible powder mixtures prepared via co-spray drying. Eur J Pharm Biopharm. 2008; 68(2):277-82.

13. Friedrich H, Fussnegger B, Kolter K, Bodmeier R. Dissolution rate improvement of poorly water-soluble drugs obtained by adsorbing solutions of drugs in hydrophilic solvents onto high surface area carriers. Eur J Pharm Biopharm. 2006; 62(2):1717.

14. Maroni A, Del Curto MD, Cerea M, Zema L, Foppoli A, Gazzaniga A. Polymeric coatings for a multiple-unit pulsatile delivery system: Preliminary study on free and applied films. Int J Pharm. 2013; 440(2):256-63.

15. Loka NC, Saripella KK, Pinto CA, Neau SH. Use of extrusion aids for successful production of Kollidon ${ }^{\circledR}$ CL-SF pellets by extrusion-spheronization. Drug Dev Ind Pharm [Internet]. 2018; 44(4):632-42. Available from: http://dx.doi.org/10.1080/03639045.2017.1405975

16. Amelian A, Szekalska M, Wilczewska AZ, Basa A, Winnicka K Preparation and characterization of orally disintegrating loratadine tablets manufactured with co-processed mixtures. Acta Pol Pharm - Drug Res. 2016;

17. Mishra SM, Rohera BD. An integrated, quality by design (QbD) approach for design, development and optimization of orally disintegrating tablet formulation of carbamazepine. Pharm Dev Technol. 2017; 22(7):889-903.

18. Sheshala R, Khan N, Darwis Y. Formulation and Optimization of Orally Disintegrating Tablets of Sumatriptan Succinate. Chem Pharm Bull (Tokyo) [Internet]. 2011; 59(8):920-8. Available from: http://joi.jlc.jst.go.jp/JST.JSTAGE/cpb/59.920?from=CrossRef

19. Loka NC, Saripella KK, Pinto CA, Neau SH. Use of extrusion aids for successful production of Kollidon $® C L-S F$ pellets by extrusion-spheronization. Drug Dev Ind Pharm. 2018; 44(4):632-42.

20. Sheshala R, Khan N, Darwis Y. Formulation and Optimization of Orally Disintegrating Tablets of Sumatriptan Succinate. Chem Pharm Bull (Tokyo). 2011; 59(8):920-8.

21. Shergill M, Patel M, Khan S, Bashir A, McConville C. Development and characterisation of sustained release solid dispersion oral tablets containing the poorly water soluble drug disulfiram. Int J Pharm [Internet]. 2016; 497(1-2):3-11. Available from:

http://dx.doi.org/10.1016/j.ijpharm.2015.11.029

22. Özgüney I, Shuwisitkul D, Bodmeier R. Development and characterization of extended release Kollidon $®$ SR minimatrices prepared by hot-melt extrusion. Eur J Pharm Biopharm. 2009; 73(1):140-5.

23. Meulenaar J, Keizer RJ, Beijnen JH, Schellens JHM, Huitema
ADR, Nuijen B. Development of an extended-release formulation of capecitabine making use of in vitro-in vivo correlation modelling. J Pharm Sci. 2014; 103(2):478-84.

24. Sakr W, Alanazi F, Sakr A. Effect of Kollidon $® S R$ on the release of Albuterol Sulphate from matrix tablets. Saudi Pharm J [Internet]. 2011; 19(1):19-27. Available from: http://dx.doi.org/10.1016/j.jsps.2010.11.002

25. Song SH, Chae BR, Sohn S Il, Yeom DW, Son HY, Kim JH, et al. Formulation of controlled-release pelubiprofen tablet using Kollidon ®SR. Int J Pharm [Internet]. 2016; 511(2):864-75. Available from:

http://dx.doi.org/10.1016/j.ijpharm.2016.07.074

26. Sahoo J, Murthy PN, Biswal S, Manik. Formulation of SustainedRelease Dosage Form of Verapamil Hydrochloride by Solid Dispersion Technique Using Eudragit RLPO or Kollidon®SR. AAPS PharmSciTech [Internet]. 2009; 10(1):27-33. Available from: http://www.springerlink.com/index/10.1208/s12249008-9175-0

27. Arias JL, Gómez-Gallo A, Delgado Á V., Ruiz MA. Kollidon®SR colloidal particles as vehicles for oral morphine delivery in pain treatment. Colloids Surfaces B Biointerfaces. 2009; 70(2):20712.

28. Palazi E, Karavas E, Barmpalexis P, Kostoglou M, Nanaki S, Christodoulou E, et al. Melt extrusion process for adjusting drug release of poorly water soluble drug felodipine using different polymer matrices. Eur J Pharm Sci [Internet]. 2018, 114:332-45. Available from: https://doi.org/10.1016/j.ejps.2018.01.004

29. Wiranidchapong C, Ruangpayungsak N, Suwattanasuk $P$ Shuwisitkul D, Tanvichien S. Plasticizing effect of ibuprofen induced an alteration of drug released from Kollidon SR matrices produced by direct compression. Drug Dev Ind Pharm. 2015; 41(6):1037-46.

30. Dzajkowska M, Hanna K, Anna M, Maja S, Dagmara D, Anna S, et al. Prolonged-release minitablets with carbamazepine preliminary observations in vitro. J Pharm Pharmacol. 2017; 69(4):471-9.

31. Engineer S, Shao ZJ, Khagani NA. Temperature/humidity sensitivity of sustained-release formulations containing Kollidon® SR. Drug Dev Ind Pharm. 2004; 30(10):1089-94.

32. Grund J, Koerber M, Walther M, Bodmeier R. The effect of polymer properties on direct compression and drug release from water-insoluble controlled release matrix tablets. Int J Pharm [Internet]. 2014; 469(1):94-101. Available from: http://dx.doi.org/10.1016/j.ijpharm.2014.04.033

33. Shergill M, Patel M, Khan S, Bashir A, McConville C. Development and characterisation of sustained release solid dispersion oral tablets containing the poorly water soluble drug disulfiram. Int J Pharm. 2016; 497(1-2):3-11.

34. Sakr W, Alanazi F, Sakr A. Effect of Kollidon $® S R$ on the release of Albuterol Sulphate from matrix tablets. Saudi Pharm J. 2011; 19(1):19-27.

35. Song SH, Chae BR, Sohn S Il, Yeom DW, Son HY, Kim JH, et al. Formulation of controlled-release pelubiprofen tablet using Kollidon®SR. Int J Pharm. 2016; 511(2):864-75.

36. Sahoo J, Murthy PN, Biswal S, Manik. Formulation of SustainedRelease Dosage Form of Verapamil Hydrochloride by Solid Dispersion Technique Using Eudragit RLPO or Kollidon®SR. AAPS PharmSciTech. 2009; 10(1):27-33.

37. Palazi E, Karavas E, Barmpalexis P, Kostoglou M, Nanaki S, Christodoulou E, et al. Melt extrusion process for adjusting drug release of poorly water soluble drug felodipine using different polymer matrices. Eur J Pharm Sci. 2018; 114:332-45.

38. Chmiel K, Knapik-Kowalczuk J, Jurkiewicz K, Sawicki W, Jachowicz R, Paluch M. A New Method to Identify Physically Stable Concentration of Amorphous Solid Dispersions (I): Case of Flutamide + Kollidon VA64. Mol Pharm. 2017; 14(10):337080 . 
39. Dreu R, Ilić I, Srčič S. Development of a multiple-unit tablet containing enteric-coated pellets. Pharm Dev Technol. 2011; 16(2):118-26.

40. Vojinović T, Medarević D, Vranić E, Potpara Z, Krstić M, Djuriš J, et al. Development of ternary solid dispersions with hydrophilic polymer and surface adsorbent for improving dissolution rate of carbamazepine. Saudi Pharm J. 2018; 26(5):725-32.

41. Tres F, Treacher K, Booth J, Hughes LP, Wren SAC, Aylott JW, et al. Indomethacin-Kollidon VA64 Extrudates: A Mechanistic Study of pH-Dependent Controlled Release. Mol Pharm. 2016; 13(3):1166-75.

42. Maddineni S, Battu SK, Morott J, Majumdar S, Murthy SN, Repka MA. Influence of Process and Formulation Parameters on Dissolution and Stability Characteristics of Kollidon® VA 64 Hot-Melt Extrudates. AAPS PharmSciTech [Internet]. 2015; 16(2):444-54. Available from: http://link.springer.com/10.1208/s12249-014-0226-4

43. Chaudhary RS, Patel C, Sevak V, Chan M. Effect of Kollidon $\mathrm{VA} 囚 64$ particle size and morphology as directly compressible excipient on tablet compression properties. Drug Dev Ind Pharm [Internet]. 2018; 44(1):19-29. Available from: https://doi.org/10.1080/03639045.2017.1371735

44. Patel D, Kumar P, Thakkar HP. Lopinavir metered-dose transdermal spray through microporated skin: Permeation enhancement to achieve therapeutic needs [Internet]. Vol. 29 Journal of Drug Delivery Science and Technology. Elsevier Ltd; 2015. 173-180 p. Available from: http://dx.doi.org/10.1016/j.jddst.2015.07.004

45. Kolter K, Flick D. Structure and dry binding activity of different polymers, including Kollidon® VA 64. Drug Dev Ind Pharm. $2000 ; 26(11): 1159-65$.

46. Castellanos Gil E, Iraizoz Colarte A, Lara Sampedro JL, Bataille B. Subcoating with Kollidon VA 64 as water barrier in a new combined native dextran/HPMC-cetyl alcohol controlled release tablet. Eur J Pharm Biopharm. 2008; 69(1):303-11.

47. Solanki NG, Tahsin M, Shah A V., Serajuddin ATM. Formulation of 3D Printed Tablet for Rapid Drug Release by Fused Deposition Modeling: Screening Polymers for Drug Release, Drug-Polymer Miscibility and Printability. J Pharm Sci
[Internet]. 2018; 107(1):390-401. Available from: https://doi.org/10.1016/j.xphs.2017.10.021

48. Rask MB, Knopp MM, Olesen NE, Holm R, Rades T. Influence of PVP/VA copolymer composition on drug-polymer solubility. Eur J Pharm Sci [Internet]. 2016; 85:10-7. Available from: http://dx.doi.org/10.1016/j.ejps.2016.01.026

49. Maddineni S, Battu SK, Morott J, Majumdar S, Murthy SN, Repka MA. Influence of Process and Formulation Parameters on Dissolution and Stability Characteristics of Kollidon® VA 64 Hot-Melt Extrudates. AAPS PharmSciTech. 2015; 16(2):444-54.

50. Chaudhary RS, Patel C, Sevak V, Chan M. Effect of Kollidon VA®64 particle size and morphology as directly compressible excipient on tablet compression properties. Drug Dev Ind Pharm. 2018; 44(1):19-29.

51. Patel D, Kumar P, Thakkar HP. Lopinavir metered-dose transdermal spray through microporated skin: Permeation enhancement to achieve therapeutic needs. Vol. 29, Journal of Drug Delivery Science and Technology. Elsevier Ltd; 2015. 173$180 \mathrm{p}$.

52. Nidhi K, Indrajeet S, Khushboo M, Gauri K, Sen DJ. Hydrotropy: A promising tool for solubility enhancement: A review. Int J Drug Dev Res. 2011; 3(2):26-33.

53. Solanki NG, Tahsin M, Shah A V., Serajuddin ATM. Formulation of 3D Printed Tablet for Rapid Drug Release by Fused Deposition Modeling: Screening Polymers for Drug Release, Drug-Polymer Miscibility and Printability. J Pharm Sci. 2018; 107(1):390-401.

54. Pilgaonkar P, Rustomjee M, Gandhi A, Jain P, Kelkar A. Patent Application Publication. Vol. 1. 2009.

55. Kanikanti V-R, Bach T, Traeubel M, Altreuther G, Rehagen M, Schmidt A. Patent Application Publication. Vol. 1. 2011.

56. Kolter K, Schonherr M, Ascherl H. United States Patent. Vol. 2. 2003.

57. Talwar N, Sen H, Staniforth J. United States Patent. Vol. 1. 2001.

58. Roser B, Blair J. United States Patent. 1998.

59. Bockbrader H, Cho Y, Santiago S, Mahjour M, Reynolds D, Shao P, et al. United States Patent. Vol. 2. 2015. 